\title{
Novel Injury Mechanism in Anoxia and Trauma of Spinal Cord White Matter: Glutamate Release via Reverse $\mathrm{Na}^{1}$-dependent Glutamate Transport
}

\author{
Shuxin Li, ${ }^{1}$ Geoff A. R. Mealing, ${ }^{2}$ Paul Morley, ${ }^{2}$ and Peter K. Stys ${ }^{1}$ \\ ${ }^{1}$ Loeb Health Research Institute, Ottawa Hospital, University of Ottawa, Ottawa, Ontario, Canada, K1Y 4K9, and \\ ${ }^{2}$ Institute for Biological Sciences, National Research Council of Canada, Ottawa, Ontario, Canada K1A OR6 \\ Spinal cord injury is a devastating condition, with much of the \\ clinical disability resulting from disruption of white matter tracts. \\ Recent reports suggest a component of glutamate excitotoxicity \\ in spinal cord injury. In this study, the role of glutamate and \\ mechanism of release of this excitotoxin were investigated in rat \\ dorsal column slices subjected to $60 \mathrm{~min}$ of anoxia or $15 \mathrm{sec}$ of \\ mechanical compression at a force of $2 \mathrm{gm}$ in vitro. The broad- \\ spectrum glutamate antagonist kynurenic acid $(1 \mathrm{~mm})$ and the \\ selective AMPA antagonist GYKI52466 (30 mM) were protective \\ glutamate in axon cylinders and oligodendrocytes by anoxia was \\ completely prevented by glutamate transport inhibition. \\ Immunohistochemistry revealed that a large component of injury \\ occurred in the myelin sheath and was prevented by AMPA \\ receptor blockade or glutamate transport inhibitors. We \\ conclude that release of glutamate by reversal of $\mathrm{Na}^{1}$ dependent \\ glutamate transport with subsequent activation of AMPA \\ receptors is an important mechanism in spinal cord white matter \\ anoxic and traumatic injury.
} against anoxia (compound action potential amplitude recovered to 56 vs $27 \%$ without drug). GYKI52466 was also effective against trauma (65 vs $35 \%$ ). Inhibition of $\mathrm{Na}^{1}$ dependent

Key words: spinal cord injury; axon; anoxia; trauma; AMPA; $\mathrm{Na}^{1}$-glutamate transport; myelin; dihydrokainate; Lglutamate transport with dihydrokainate or L-transpyrrolidine2,4-dicarboxylic acid (1 mm each) protected against anoxia (6575 vs $25 \%$ ) and trauma (70 vs $35 \%$ ). The depletion of cytosolic White matter tracts within the mammalian CNS play the very important role of transmitting information to and from neurons in the CNS. The spinal cord, arguably the most important white matter tract, is subject to traumatic injury with .10,000 new cases per year occurring in the United States alone (Gibson, 1992). Although both the central gray matter in the cord as well as surrounding axonal tracts suffer damage from the mechanical trauma and secondary ischemia (Tator and Koyanagi, 1997), disruption of axonal connections spanning even a small segment can result in severe and widespread disability. The underlying mechanisms leading to axonal dysfunction in spinal cord injury (SCI) are poorly understood, and current treatment is of limited efficacy. Therefore, understanding how axons are irreversibly damaged in this condition is of paramount importance to devise more effective treatments for the acute phase.

Recent reports using in vitro and in vivo SCI models indicate that voltage-gated $\mathrm{Na}^{1}$ channels play an important role in mediating cellular injury in SCI (Agrawal and Fehlings, 1996; Teng and Wrathall, 1997), similar to observations in anoxic axons (Stys et al., 1992; Imaizumi et al., 1997). In addition, injury is also dependent on excitotoxic mechanisms involving AMPA and kainate receptors (Agrawal and Fehlings, 1997; Wrathall et al., 1997). However, the precise cellular targets for glutamate toxicity

Received April 19, 1999; revised May 6, 1999; accepted May 6, 1999.

P.K.S. is supported by a Career Investigator award from the Heart and Stroke Foundation of Ontario. S.L. is supported by a studentship from the Natural Sciences and Engineering Research Council of Canada.

Correspondence should be addressed to Dr. Peter K. Stys, Loeb Health Research Institute, Division of Neuroscience, 725 Parkdale Avenue, Ottawa, Ontario, Canada, K1Y 4K9. E-mail: pstys @lri.ca

Copyright (C) 1999 Society for Neuroscience $\quad$ 0270-6474/99/190001- $\$ 05.00 / 0$

in white matter are not known, nor is there an explanation of how glutamate might be released in this tissue devoid of synaptic elements. In this study, we demonstrate that in isolated spinal dorsal columns endogenous glutamate is released by reversal of $\mathrm{Na}^{1}$-dependent glutamate transport. We also show that the myelin sheath is a target for transpyrrolidine-2,4-dicarboxylic acid; GYKI52466; kynurenic acid

glutamate-mediated excitotoxicity through activation of AMPA receptors. This mechanism would unite and explain the observations that either $\mathrm{Na}^{1}$ channel blockade or AMPA antagonists are neuroprotective in $\mathrm{SCI}$, because $\mathrm{Na}^{1}$ entry through the former route would induce reverse glutamate transport and cause release of potentially large amounts of this excitotoxin from cytosolic compartments.

\section{MATERIALS AND METHODS}

Electrophysiology. Adult Long-Evans male rats (200-250 gm) were anesthetized with sodium pentobarbital, and a laminectomy was performed between T3 and T11. Rats were then perfused intra-aortically with $500 \mathrm{ml}$ of choline-substituted zero- $\mathrm{Na}^{1}$, zero- $\mathrm{Ca}^{21}$ solution. A $30 \mathrm{~mm}$ section of spinal cord was rapidly removed and placed in cold $\left(4-6{ }^{\circ} \mathrm{C}\right)$

This article is published in The Journal of Neuroscience, Rapid Communications Section, which publishes brief, peerreviewed papers online, not in print. Rapid Communications are posted online approximately one month earlier than they would appear if printed. They are listed in the Table of Contents of the next open issue of JNeurosci. Cite this article as: JNeurosci, 1999, 19:RC16 (1-9). The publication date is the date of posting online at www.jneurosci.org.

http://www.jneurosci.org/cgi/content/full/3240 
Figure 1. A, Schematic of recording arrangement. Dorsal column slices were incubated in an in vitro recording chamber. Stimulating and recording surface electrodes were used to evoke compound propagated action potentials. $B$, Representative tracings of compound action potentials shown at intervals of $1 \mathrm{hr}$ recorded over $3 \mathrm{hr}$ demonstrating the stability of the shape and amplitude, even with repositioning of the electrodes to allow study of multiple slices during the same experiment (see Materials and Methods). $C$, Graph quantitatively showing stable peak amplitudes over $3 \mathrm{hr}$ at $37^{\circ} \mathrm{C}$.
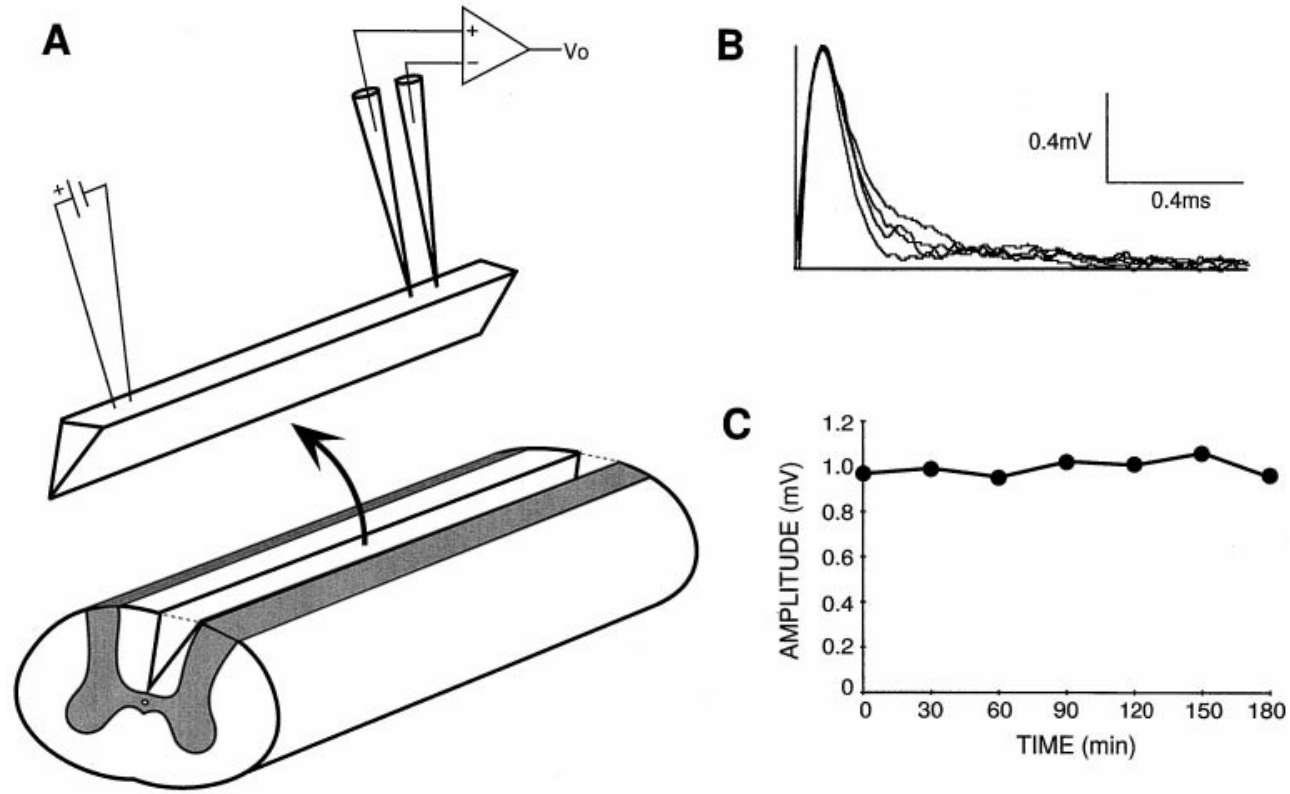

zero- $\mathrm{Na}^{1}$, zero-Ca ${ }^{21}$ solution bubbled with $95 \% \mathrm{O}_{2}$ and $5 \% \mathrm{CO}_{2}$. Dorsal column sections were excised and placed in an interface recording chamber bathed in $\mathrm{Ca}^{21}$-free artificial CSF (aCSF) and slowly warmed to $37^{\circ} \mathrm{C}$. Perfusate was then switched to aCSF (in mM: $126 \mathrm{NaCl}, 3.0 \mathrm{KCl}, 2.0 \mathrm{MgSO}_{4}, 26 \mathrm{NaHCO}_{3}, 1.25$ $\mathrm{NaH}_{2} \mathrm{PO}_{4}, 2.0 \mathrm{CaCl}_{2}$, and 10 dextrose, $\mathrm{pH}$ 7.4), and control readings were taken 30 min later.

Propagated compound action potentials (CAPs) were evoked using a bipolar silver wire stimulating electrode (50 msec and typically $70 \mathrm{~V}$ ) delivered once every $30 \mathrm{~min}$, and extracellular recordings were performed using large-tipped glass microelectrodes filled with $150 \mathrm{~mm} \mathrm{NaCl}$ (Fig. 1). To allow recording of multiple slices during a single experiment, the stimulation and recording sites were marked with a small amount of neutral red dye to allow accurate repositioning of the electrodes. Evoked CAPs were digitized, stored, and analyzed using WaveTrak software (Stys, 1994). The functional integrity of the dorsal column was quantitated by measuring peak CAP amplitude.

Potential direct effects of glutamate transport inhibitors on AMPA currents were studied by patch clamp in cultured rat cortical neurons as previously described (Mealing et al., 1999). The bathing solution contained (in mM): 140 $\mathrm{NaCl}, 5 \mathrm{KCl}, 1 \mathrm{CaCl}_{2}, 10 \mathrm{HEPES}, 3$ glucose, and $0.001 \mathrm{TTX}, 0.001$ strychnine, $\mathrm{pH}$ 7.4. The pipette solution contained (in mM): $140 \mathrm{CsCl}, 1.1$ EGTA, 10 HEPES, and $2 \mathrm{Mg}$-ATP, pH 7.2. Solutions were applied to the cell through a computer-controlled manifold. Wholecell currents were measured at a holding potential of $260 \mathrm{mV}$ after a $0.5 \mathrm{sec}$ application of cyclothiazide $(100 \mathrm{~mm})$, then $1 \mathrm{sec}$ AMPA (100 mM) plus cyclothiazide, followed $10 \mathrm{sec}$ later by a second application of AMPA plus cyclothiazide with or without $1 \mathrm{~mm}$ dihydrokainic acid or L-trans-pyrrolidine-2,4-dicarboxylic acid (Tocris Cookson, Bristol, UK).

In vitro anoxia and SCI. Drug-containing solutions were applied beginning $60 \mathrm{~min}$ before dorsal column injury and continued until $15 \mathrm{~min}$ after injury, after which tissue was washed with aCSF. Injury was induced by anoxia or trauma. Anoxia was achieved by switching to a $95 \% \mathrm{~N}_{2}$ and $5 \% \mathrm{CO}_{2}$ atmosphere for 60 min and then reoxygenating for $2 \mathrm{hr}$. Trauma was induced by compression with a custom-made aneurysm clip calibrated to a closing force of $2 \mathrm{gm}$ (David Walsh, Oakville, Ontario, Canada), applied for $15 \mathrm{sec}$ between the stimulation and recording sites (Agrawal and Fehlings, 1997). GYKI52466 (Research Biochemicals, Natick, MA), dihydrokainic acid, and L-trans-pyrrolidine-2,4dicarboxylic were dissolved in $0.1 \mathrm{~N} \mathrm{HCI}$ (GYKI52466) or $0.1 \mathrm{~N} \mathrm{NaOH}$ and then added to aCSF to the desired final concentration. Kynurenic acid (Research Biochemicals) was dissolved directly into aCSF.

Immunohistochemistry of glutamate and damaged myelin. To directly examine to what extent the myelin sheath was affected by our injury paradigms, we used rabbit antiserum raised against degenerated myelin basic protein (antiEP; a generous gift from Dr. Pat McGeer, University of British Columbia), which was found to stain damaged, but not intact, white matter regions (Matsuo et al., 1997). Tissue was fixed in $4 \%$ paraformaldehyde for $24 \mathrm{hr}$ and then cryoprotected for $48 \mathrm{hr}$ in PBS, $\mathrm{pH}$

7.4 , containing $20 \%$ glycerol at $4^{\circ} \mathrm{C}$. Slices were then dissected into smaller pieces and preincubated in $10 \%$ Triton X-100 for $30 \mathrm{~min}$, followed by $4 \%$ normal goat serum (NGS) with $0.1 \%$ Triton X-100, and PBS for blocking for 1 $\mathrm{hr}$ at room temperature. The sections were incubated for $24 \mathrm{hr}$ at $4{ }^{\circ} \mathrm{C}$ with primary antiserum diluted in $2 \%$ NGS with $0.1 \%$ Triton X-100 and PBS at a concentration of 1:100 for anti-EP and for anti-mouse neurofilament 160. Alexa 594 goat anti-rabbit (1:200) and Alexa 488 goat anti-mouse (1:400; Molecular
Probes, Eugene, OR) were used for secondaries. Controls consisted of primary or secondary antibodies omitted.

The protocol for glutamate immunohistochemistry was similar, except that $0.5 \%$ glutaraldehyde was used as an additional fixative. A rabbit anti-glutamate polyclonal antibody (Chemicon, Temecula, CA) was used at 1:500 dilution to label cytosolic glutamate. Double staining with monoclonals against neurofilament 160 (Sigma, St. Louis, MO), 2939cyclic nucleotide 39phosphohydrolase (CNPase, Chemicon), and antiglial fibrillary acidic protein (GFAP; Boehringer Mannheim, Indianapolis, IN) allowed localization of axon cylinders, oligodendrocytes (Trapp et al., 1988), and astrocytes, respectively. Antiserum concentrations, incubation times, and all tissue preparation were identical between groups to reduce artifactual changes in observed fluorescence. In addition, confocal parameters (pinhole size, laser power, gain, and black level) were constant to allow for valid comparisons between treatment groups. Images were analyzed using NIH Image 1.61 (http://rsb.info.nih. gov/nihimage/default.html). Regions of interest were selected according to reference labels (i.e., neurofilament 160, CNPase, and GFAP) and mean fluorescence values, reflecting glutamate concentration in that area, computed from the "glutamate" channel.

Immunohistochemistry of glutamate transporters. Rats were perfused intraaortically with cold $0.1 \mathrm{~m} \mathrm{PBS,} \mathrm{pH} 7.4$, followed by $4 \%$ paraformaldedyde in PBS after laminectomy under pentobarbital anesthesia. The process was similar to the previous section, except that the slices were also pretreated with $95 \%$ ethanol and 5\% acetic acid for $60 \mathrm{~min}$. The primary antibodies were diluted in $2 \%$ NGS with $0.1 \%$ Triton X-100 and PBS at a concentration of $5 \mathrm{mg} / \mathrm{ml}$ for anti-GLT1 ( $\mathrm{N}$ terminus; Alpha Diagnostic International, San Antonio, TX), $0.98 \mathrm{mg} / \mathrm{ml}$ for anti-GLAST ( $\mathrm{N}$ terminus), $0.49 \mathrm{mg} / \mathrm{ml}$ for anti-EAAC1 (C terminus; courtesy of Dr. Jeffrey Rothstein, Johns Hopkins University, Baltimore, MD) (Rothstein et al., 1994; Furuta et al., 1997), 1:2000 for antimyelin basic protein (MBP; Sternberger Monoclonals, Lutherville, MD), and 1:100 for GFAP. Images were collected on a Bio-Rad (Hercules, CA) 1024 confocal laser scanning microscope with a 603 oil-immersion lens (Olympus Optical, Tokyo, Japan).

Statistics. All data are expressed as means 6 SD. Statistical differences were calculated by ANOVA with Dunnett's test for comparisons with a common control group or ANOVA with Bonferroni correction for multiple comparisons. Reported $\mathrm{n}$ values represent number of individual dorsal column slices studied with each treatment. 

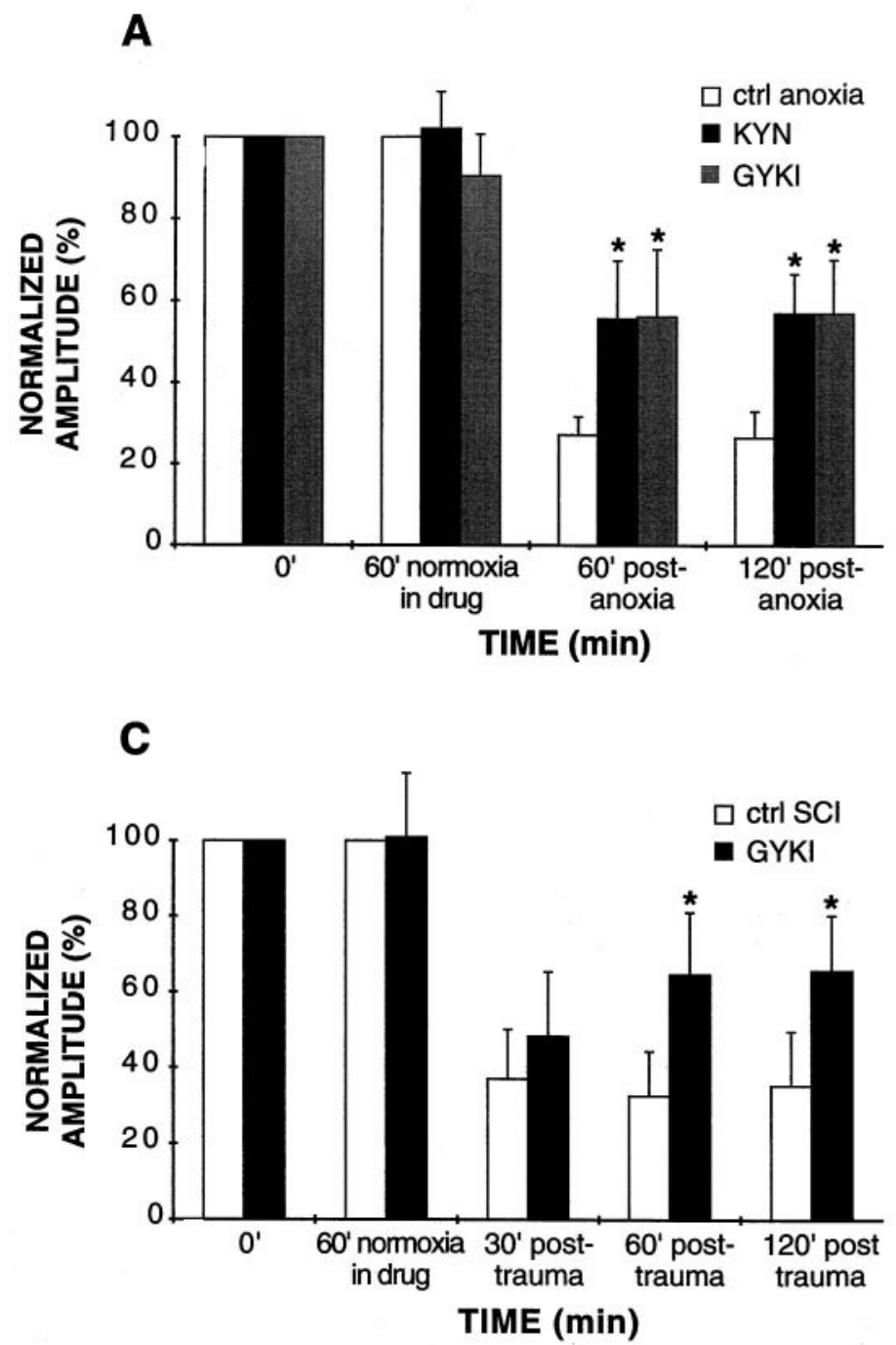

B

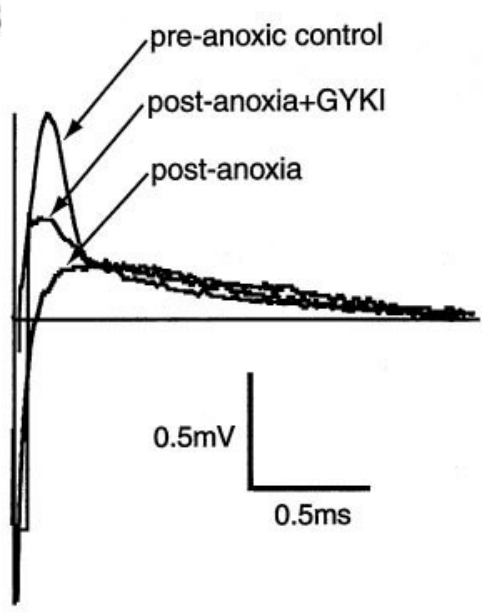

D

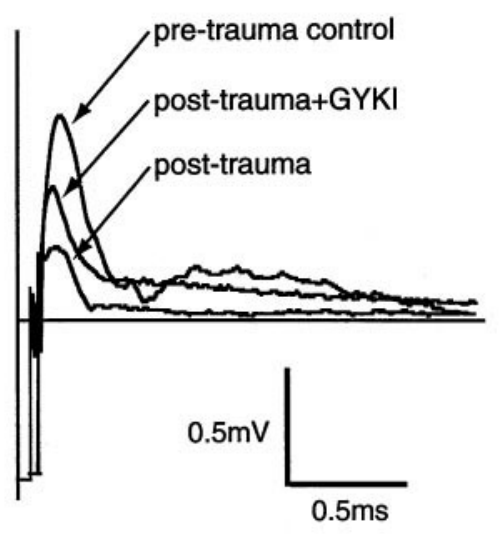

Figure 2. Bar graphs illustrating recovery of compound action potential amplitudes recorded from dorsal column slices in vitro after 60 min of anoxia (A) or 15 sec of traumatic compression at $2 \mathrm{gm}(C)$. Peak amplitudes were normalized to baseline responses recorded at time 0 (see Materials and Methods). Drugs were applied beginning $60 \mathrm{~min}$ before and continued until $15 \mathrm{~min}$ after injury (anoxia or trauma). Slices were exposed to $60 \mathrm{~min}$ of anoxia, and compound action potentials were measured at 60 and $120 \mathrm{~min}$ of reoxygenation ( 609 and 1209 post-anoxia bars). In aCSF alone, amplitudes recovered to ;27\% of preanoxic control (ctrl anoxia; $n 5$ 12), whereas recovery was significantly enhanced to ;55\% of control by kynurenic acid (KYN, $1 \mathrm{~mm} ; n 56)$ or GYKI52466 (GYKI, 30 mM; $n 57)$ (A). Similarly, GYKI52466 ( $n 5$ 14) improved recovery after trauma from 35\% (ctrl SCI; $n 513$ ) to 65\% of preinjury control amplitude. B, D, Representative compound action potential tracings obtained after anoxia or trauma. These data indicate that endogenous glutamate contributes to functional injury of isolated dorsal columns during anoxia and trauma, acting mainly through AMPA receptors. * $p, 0.01$ compared with time-matched readings of slices injured in the absence of drug.

\section{RESULTS AMPA receptors contribute to injury of} dorsal white matter

Electrophysiological recording of dorsal column slices showed a reduction of CAP amplitude to ;25\% of control after 60 min of anoxia followed by reoxygenation and to $; 35 \%$ of control after a $15 \mathrm{sec}$ traumatic clip compression (Fig. 2). Uninjured controls displayed ,5\% change in mean CAP amplitude during $3 \mathrm{hr}$ in vitro (Fig. 1). To confirm a role of glutamate receptors, tissue was exposed to $1 \mathrm{~mm}$ kynurenic acid, a broad-spectrum inhibitor of both NMDA and non-NMDA ionotropic receptors. This agent improved recovery of CAP amplitude after 60 min of anoxia to $56 \%$ of control versus $27 \%$ without drug ( $p$ , 0.01; Fig. 2). GYKI52466 (30 mM), a selective AMPA glutamate receptor antagonist (Paternain et al., 1995), significantly improved the recovery of CAP amplitude after anoxia (56 vs $27 \%$ of control CAP amplitude; $p, 0.01$ ) or trauma (65 vs $35 \%$ without drug; $p, 0.01$ ), indicating that glutamate partially contributes to white matter injury through AMPA receptors during anoxia or trauma.

Figure 3 shows representative fluorescence images of normal dorsal column slices incubated under normoxic conditions for $3 \mathrm{hr}$ in vitro (Fig. $3 A$ ) and tissue injured by anoxia (Fig. $3 B-E$ ) or SCI (Fig. $3 F, G$ ).
Green signal is neurofilament outlining axon cylinders, and the red channel indicates damaged myelin stained with serum specific for degenerated myelin basic protein (see Materials and Methods). Figure $3, D$ and $E$, shows that myelin damage was largely prevented by AMPA receptor blockade with GYKI52466.

\section{Reverse $\mathrm{Na}^{1}$-dependent glutamate transport contributes to glutamate release during anoxia and SCI}

The results presented above suggest that endogenous glutamate is released from cytoplasmic compartments in isolated spinal white 
Figure 3. Immunohistochemistry of dorsal column axons stained for neurofilament ( green) outlining axon cylinders and damaged myelin detected by antiserum raised against degenerated myelin basic protein (red). A, Control sections show virtually no myelin damage. A $60 \mathrm{~min}$ anoxic exposure caused significant myelin damage as shown by strong immunoreactivity surrounding many axon cylinders $(B, C$, arrowheads). $C$, Higherpower view of a single damaged axon. The AMPA receptor blocker GYKI52466 greatly reduced the degree of anoxic myelin damage $(D, E)$. Sections from the injury focus showed that traumatic compression $(S C I)$ also resulted in damage to myelin $(F$, red signal) as well as disruption of axon cylinders as evidenced by distorted neurofilament profiles. Trauma in the presence of the $\mathrm{Na}^{1}$-dependent glutamate transport inhibitor L-trans-pyrrolidine2,4dicarboxylic acid (SCI 1 PDC) significantly reduced myelin injury $(G)$. Bars, $10 \mathrm{~mm}$.

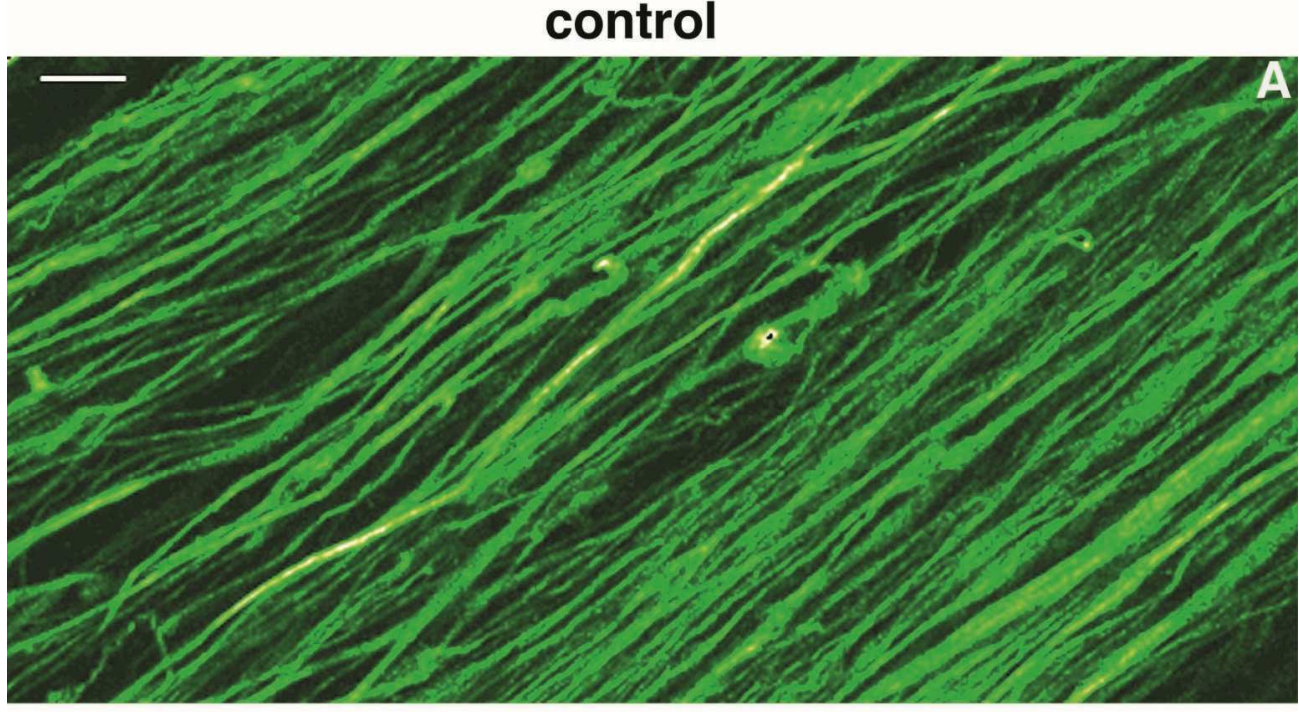

anoxia
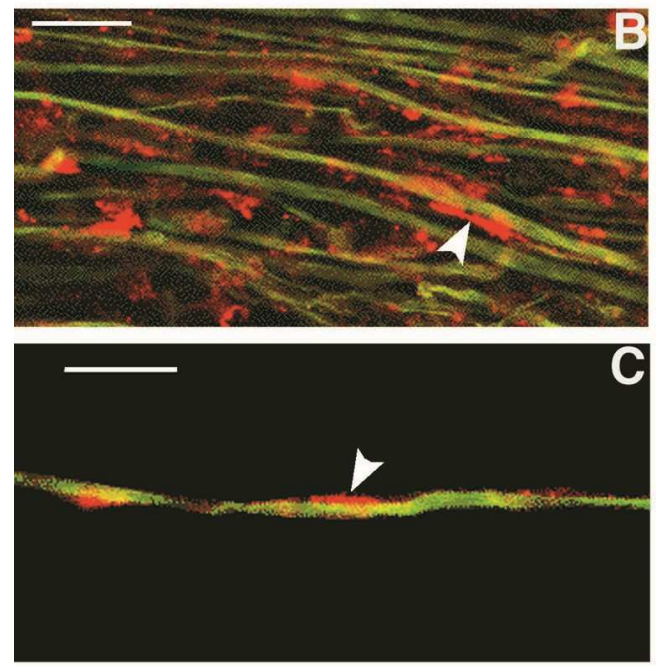

$\mathrm{SCl}$

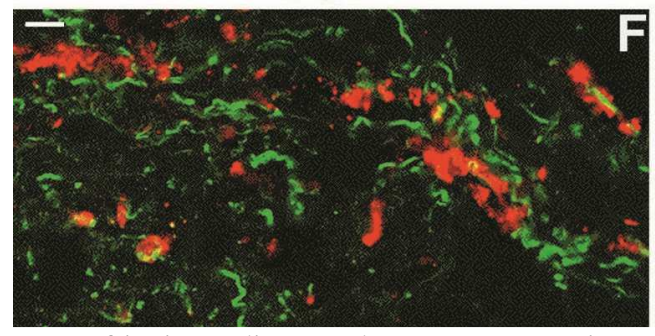

anoxia + GYKI
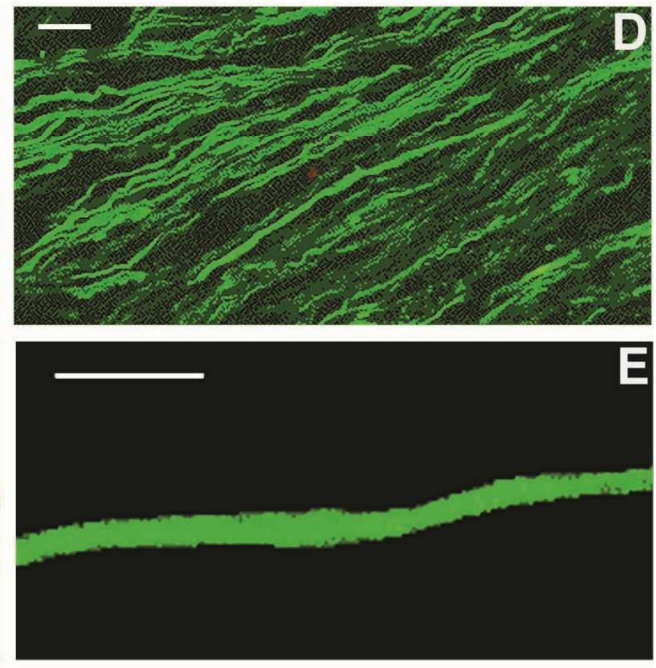

$\mathrm{SCI}+\mathrm{PDC}$

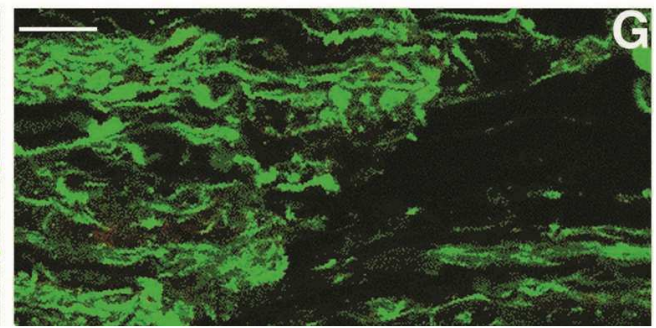

neuroprotective against in vitro anoxia or SCI, increasing recovery of CAP amplitudes twofold to threefold compared with untreated injured tissue (Fig. 4A,B). The degree of myelin damage after in vitro SCI was markedly reduced by gluta-

\section{.}

membrane depolarization in white matter tracts (LoPachin and Stys, 1995; Leppanen and Stys, 1997; Blight and LoPachin, 1998) that may induce release of glutamate in a $\mathrm{Ca}^{21}$ independent manner through reversal of $\mathrm{Na}^{1}$-dependent glutamate transport, as has been shown in gray matter (Roettger and Lipton, 1996). To test this hypothesis, we examined the effect of glutamate transport inhibition on the recovery of dorsal white matter after in vitro anoxia or SCI. L-trans-Pyrrolidine2,4dicarboxylic acid is a transportable antagonist (Griffiths et al., 1994); therefore the tissue was preloaded, probably by heteroexchange with glutamate, so that sufficient levels of inhibitor would be available at the cytoplasmic face to inhibit glutamate release. In contrast, dihydrokainate is a nontransportable inhibitor of the GLT1 subtype of glutamate transporter acting at the extracellular surface (Arriza et al., 1994). Both inhibitors (applied at $1 \mathrm{~mm}$ ) were significantly 
A
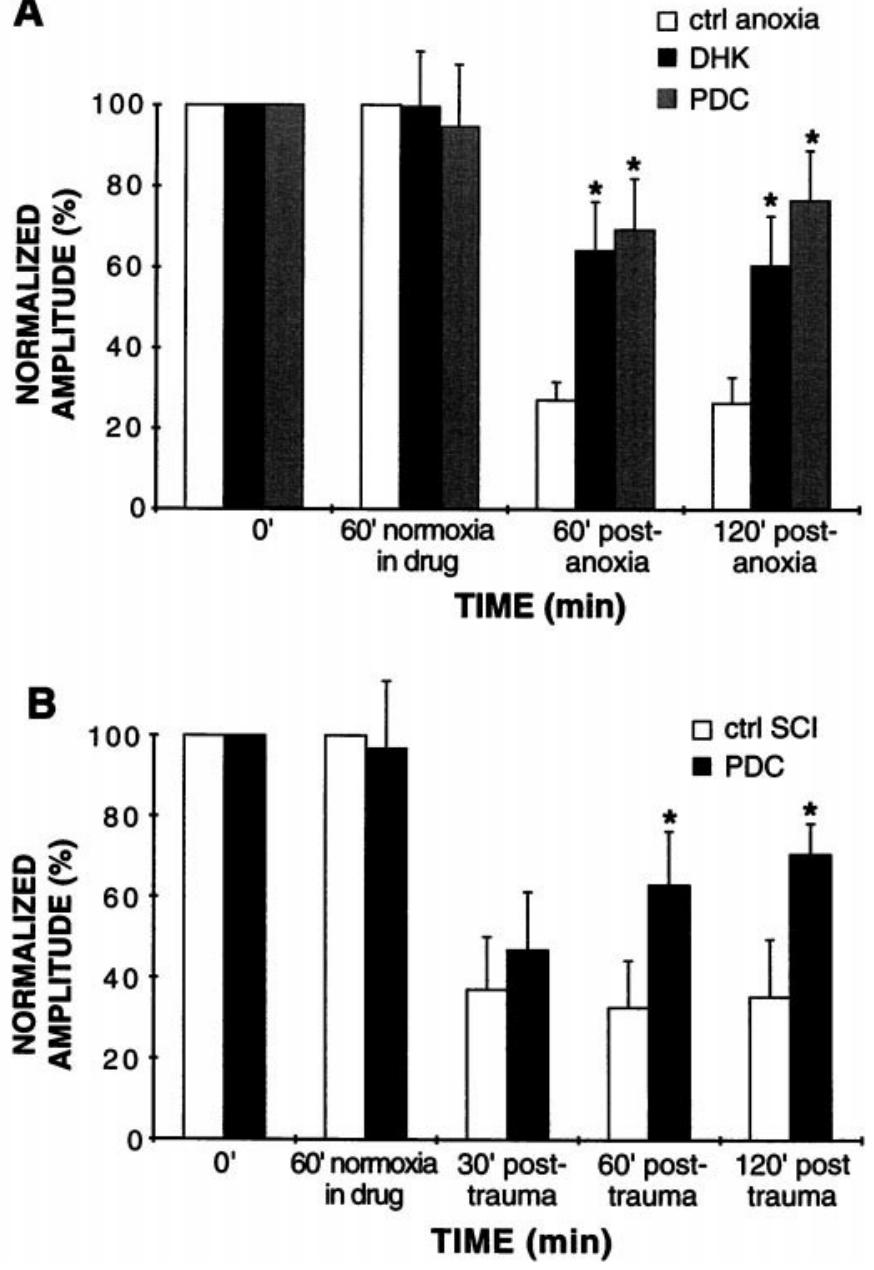

C

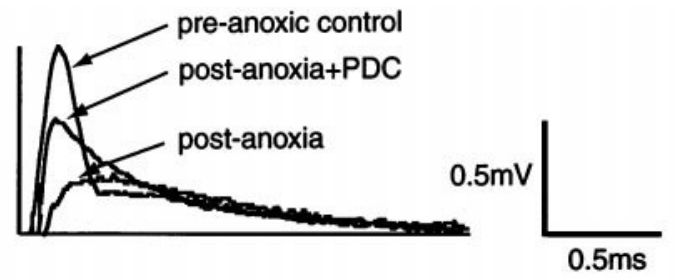

D

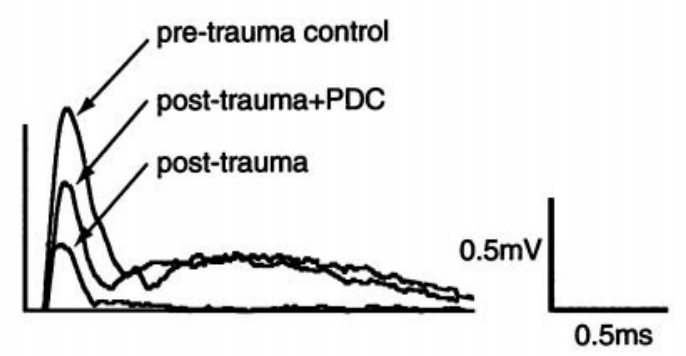

E

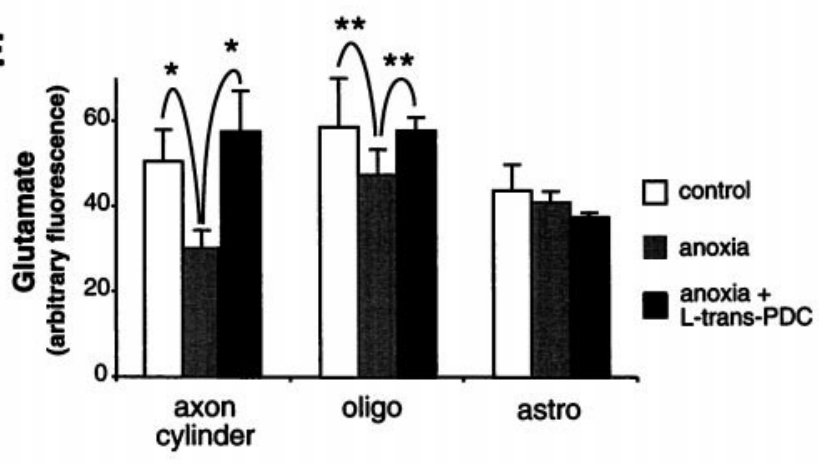

Figure 4. Effect of $\mathrm{Na}^{1}$-dependent glutamate transport inhibitors on the recovery of compound action potentials after anoxia or trauma. Drugs were applied beginning $60 \mathrm{~min}$ before and continued until $15 \mathrm{~min}$ after injury. Neither inhibitor [dihydrokainate (DHK) or L-trans-pyrrolidine-2,4-dicarboxylic acid (PDC), both 1 mM] had any significant effect on preinjury responses (609 normoxia in drug bars). Both agents improved compound action potential amplitudes significantly after 60 min of anoxia $(A)$ or a $15 \mathrm{sec}$ traumatic compression $(B) .{ }^{*} p, 0.01$ compared with time-matched readings of slices injured in the absence of drug. $C, D$, Representative compound action potential tracings. Bar graph in E, Summary of semiquantitative confocal glutamate immunofluorescence results in three intracellular compartments. Anoxia caused significant depletion of cytosolic glutamate in axon cylinders and oligodendrocytes but not astrocytes; this depletion was completely prevented by PDC $\left(* p, 0.01 ; *^{*} p, 0.05\right)$. These results indicate that endogenous glutamate is released by reverse operation of $\mathrm{Na}^{1}$-dependent glutamate transporters during anoxic or traumatic injury. ( $n$ values: $A$, ctrl anoxia, $12 ; D H K, 7 ; P D C, 7 ; B, c t r l ~ S C I, 13, P D C, 7 ; E$, minimum of 10 images, each containing multiple regions of interest per group).

mate transport inhibition (Fig. $3 F, G$ ), although the disruption of axon cylinders shown by neurofilament staining appeared unchanged. Confocal fluorescence was used to estimate semiquantitatively the cytosolic glutamate concentrations in axon cylinders and glial cell bodies and processes after $1 \mathrm{hr}$ of anoxia. Figure $4 E$ shows that glutamate levels were significantly reduced in axon cylinders and oligodendrocytes by anoxia, and this reduction was completely reversed by L-trans-pyrrolidine-2,4-dicarboxylic acid. Astrocytic glutamate was not significantly altered by anoxia.

To exclude the possibility that glutamate transport inhibitors exerted their neuroprotective actions through interaction directly with AMPA receptors, the effects of these agents on AMPAinduced currents were measured by patch clamp in cultured neurons. Steady-state currents were increased slightly to 11165 and $120611 \%$ of control by $1 \mathrm{~mm}$ L-trans-pyrrolidine-2,4dicarboxylic acid and dihydrokainate, respectively (data not shown). This was not statistically significant.

\section{Dorsal white matter possesses three subtypes of $\mathbf{N a}^{1}$} dependent glutamate transporters: GLT1, GLAST, and EAAC1

The previous results provide pharmacological evidence for the presence of $\mathrm{Na}^{1}$-dependent glutamate transporters in spinal white matter. More direct evidence was provided by immunohistochemistry using specific antisera raised against the GLT1, GLAST, and EAAC1 subtypes. Figure 5 illustrates the distributions of the various isoforms. Consistent with previous reports (Rothstein et al., 1994), GLT1 was found in GFAP-positive astrocytes at high density (Fig. 5B), with fainter stain seen within the axoplasm of myelinated axons (Fig. 5A). GLT1 was not found in myelin, in contrast to GLAST, which was present throughout the thickness of the sheath (Fig. 5C). GLAST was also observed in astrocytes (Fig. $5 D$ ). EAAC1, a predominantly neuronal isoform, was not present in myelin, and label was only weakly observed in some GFAP-positive astrocytes (Fig. $5 F$ ). There was 
GLT1 + MBP

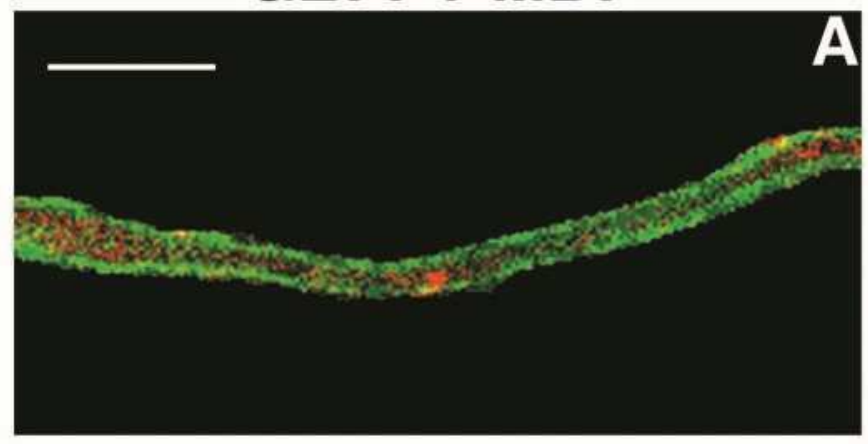

GLAST + MBP

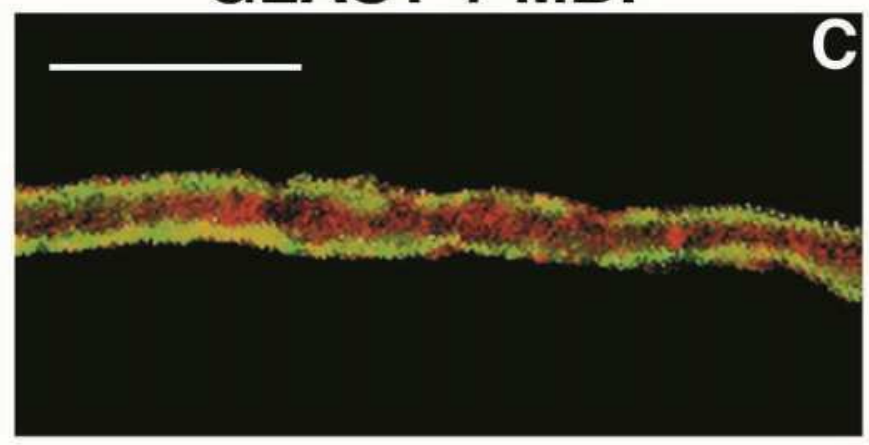

EAAC1 + MBP

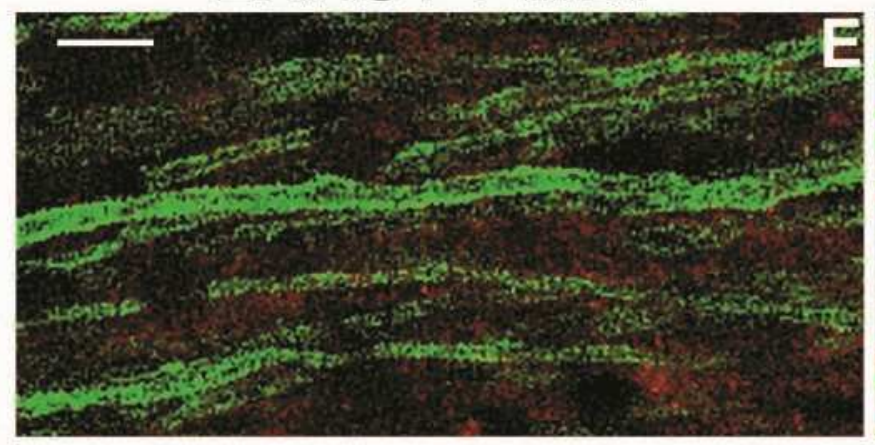

GLT1 + GFAP

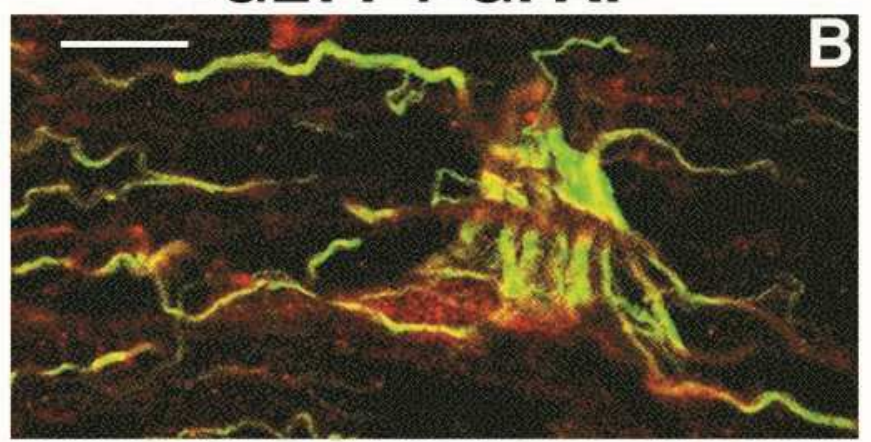

GLAST + GFAP

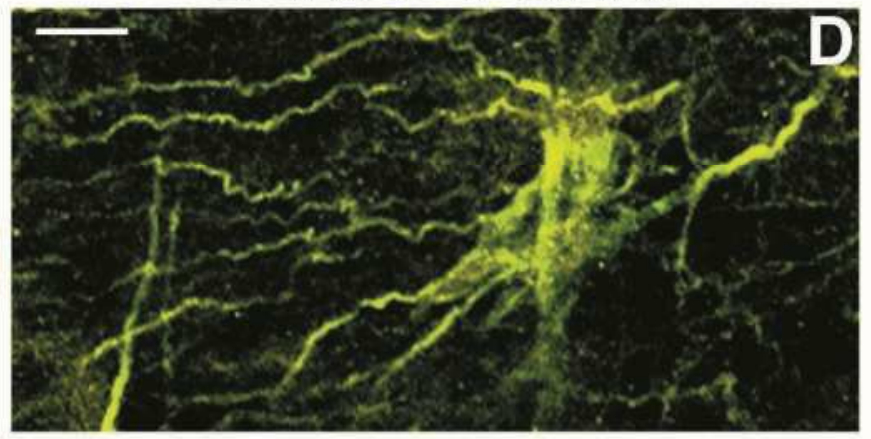

EAAC1 + GFAP

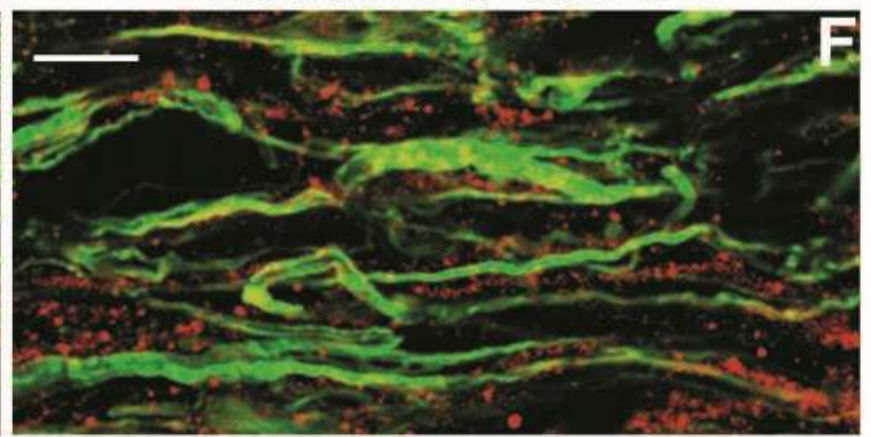

Confocal microscopic images of dorsal columns showing representative immunohistochemistry of three isoforms of glutamate transporter (red) double stained with standard markers ( green). A, Individual myelinated axon showing faint GLT1 signal within the axon cylinder but no detectable stain within the myelin sheath outlined using anti-MBP antibodies. $B$, GLT1 was present at high density in cell bodies and processes of astrocytes stained with GFAP, resulting in yellow signal indicating colocalization of these two proteins. $C$, Single myelinated axon showing GLAST signal throughout the full thickness of the myelin sheath, with stain within the axon cylinder itself in some fibers. $D$, GLAST and GFAP colocalized in all GFAP-positive astroglia. E, The EAAC1 isoform did not localize to the myelin sheath, nor was it convincingly found within the axon cylinders. $F$, GFAP-positive astrocytes occasionally displayed EAAC1 immunoreactivity, which was much less consistent than with GLT1 and GLAST. There was considerable intervening stain outside myelin and astrocytic regions (see Results). Bars, 10 mm. considerable intervening stain outside myelin and astrocytic regions (Fig. $5 E$ ), potentially associated with unmyelinated axons, axoplasm of myelinated fibers, or oligodendroglial processes. The precise localization of this signal was not investigated further.

\section{DISCUSSION}

Central myelinated axons are susceptible to a variety of insults, the commonest being anoxia and ischemia, trauma, and demyelination. Indeed, these seemingly disparate injury modalities may share common mechanisms; for example, traumatic spinal cord injury consists of the acute mechanical disruption of spinal axons, which is followed by a delayed ischemic component (Tator and Koyanagi, 1997). The cellular mechanisms of axonal injury are not as well understood as those in gray matter, in which excitotoxicity leading to
$\mathrm{Ca}^{21}$-mediated injury, free radical generation, and delayed apoptosis are thought to be the main avenues by which neurons succumb to anoxia and ischemia. In anoxic central myelinated axons, in contrast, excessive $\mathrm{Na}^{1}$ influx through noninactivating $\mathrm{Na}^{1}$ channels causes $\mathrm{Ca}^{21}$ overload largely through reverse $\mathrm{Na}^{1}-\mathrm{Ca}^{21}$ exchange. The excessive $\mathrm{Ca}^{21}$ influx in turn triggers a variety of $\mathrm{Ca}^{21}$-dependent biochemical pathways leading to irreversible axonal damage (Imaizumi et al., 1997; Stys and LoPachin, 1998).

The precise role of glutamate-mediated excitotoxicity in white matter injury is poorly understood. The NMDA receptor antagonist ketamine failed to show any neuroprotective effects against in vitro optic nerve anoxia at concentrations low enough to ensure relative specificity for these receptors (Ransom et al., 1990). Recent reports, 
however, indicate that glutamate, acting through non-NMDA receptors, may play a direct role in white matter injury. For example, white matter oligodendroglia possess both AMPA and kainate receptors at densities sufficient to cause significant injury when activated by specific agonists (Matute et al., 1997; McDonald et al., 1998). In addition, in vitro oxygen and glucose deprivation causes damage to cultured oligodendroglia that is dependent on AMPA and kainate receptors (McDonald et al., 1998). By extension, it may be possible that the myelin sheath itself possesses AMPA and kainate receptors and may be directly susceptible to injury from high concentrations of ambient glutamate released from compromised axon cylinders or glia.

Traumatic injury of spinal cord white matter also appears to depend on glutamate. Using an in vivo contusive model, Wrathall and colleagues found a reduction in white matter pathology (Rosenberg et al., 1999) and a parallel behavioral improvement (Wrathall et al., 1994), in animals treated with the AMPA and kainate antagonist 2,3dihydroxy-6-nitro-7-sulfamoylbenzo (f)quinoxaline (NBQX). The neuroprotective effect of AMPA and kainate receptor blockade was also observed in an in vitro model of isolated dorsal column compression. Without the potentially confounding influence of adjacent gray matter, dorsal columns were found to be injured by exogenously applied AMPA or kainate, and compressive injury was dependent in part on AMPA and kainate receptor activation as evidenced by a partial neuroprotective effect of CNQX or NBQX (Agrawal and Fehlings, 1997). Taken together, these findings implicate AMPA and kainate receptor activation as one component of the injury cascade in white matter. In this study, we wished to explore both the mode of glutamate release, target receptors, and loci of injury in spinal white matter anoxia and trauma.

Using an electrophysiological measure of functional integrity, a $1 \mathrm{hr}$ anoxic exposure followed by 1 or $2 \mathrm{hr}$ of reoxygenation resulted in irreversible depression of CAP amplitude to $27 \%$ of preanoxic control values. This is very close to the level reported in a similar in vitro model (Imaizumi et al., 1997). The broadspectrum glutamate receptor antagonist kynurenic acid or the relatively specific AMPA receptor antagonist GYKI52466 (Paternain et al., 1995), both provided significant and virtually identical neuroprotection from anoxia, with CAP amplitudes recovering to greater than twice that seen without antagonist. This is consistent with a role of AMPA but not NMDA receptors in this paradigm. AMPA receptors also appeared to play a significant role in trauma. A 2 gm compression injury in vitro resulted in an irreversible reduction of CAP amplitude to $35 \%$ of control levels in our study. This injury was identical to that found in a recent in vitro study using guinea pig spinal cord slices at physiological temperature (Blight and LoPachin, 1998) but was far greater than observations of Agrawal and Fehlings (1997), who found reductions of CAP amplitude to only $70 \%$ of control. However, the latter group performed their experiments at temperatures significantly below physiological (typically $25^{\circ} \mathrm{C}$ ), and it is likely that the hypothermia reduced the degree of injury. Despite a greater degree of damage at physiological temperature in our experiments, GYKI52466 also conferred marked neuroprotection after clip compression. Moreover, in contrast to a previous report (Agrawal and Fehlings, 1997), the protective effect was sustained for the duration of our in vitro recording. Together, our data strongly implicate receptors of the AMPA class in both anoxic and traumatic injury of spinal dorsal columns.

Electrophysiology provides a sensitive means to study the function of axonal tracts but gives little information about the structural integrity of subcellular elements. We used antiserum raised against an amino acid sequence of myelin basic protein that is inaccessible in normal myelin but is unmasked in degenerated myelin in white matter areas damaged by immune attack or ischemia (Matsuo et al., 1997). Control tissue maintained in vitro showed virtually no staining, whereas anoxia or trauma induced obvious myelin damage (Fig. 3B,C,F). These changes were prevented by selective AMPA inhibition, not only indicating that this subtype of ionotropic glutamate receptor contributes to myelin injury, but also pointing to an endogenous source of glutamate. We cannot exclude glutamate-mediated injury to other elements such as astrocytes, oligodendroglial cell bodies, and/or the axon cylinder itself. Indeed it is quite possible that glia suffered glutamate-dependent injury, because these cells are known to be sensitive to excitotoxic insults mediated by AMPA and kainate receptors (Matute et al., 1997; McDonald et al., 1998).

Because our preparation excludes spinal gray matter, the source of endogenous glutamate must be from glia or axons. Cytoplasm, including axoplasm, is known to contain millimolar concentrations of glutamate that far exceed the low micromolar levels in brain extracellular space (Fonnum, 1984; Attwell et al., 1993). In the absence of synaptic machinery and barring frank membrane rupture, there are two ways that this amino acid could be released: efflux through volume-sensitive anion channels (Rutledge et al., 1998) or by reversal of $\mathrm{Na}^{1}$-dependent glutamate transport (Attwell et al., 1993). The latter pathway transports glutamate or aspartate with $\mathrm{Na}^{1}$ and $\mathrm{H}^{1}$ in exchange for $\mathrm{K}^{1}$ in an electrogenic manner (Zerangue and Kavanaugh, 1996; Levy et al., 1998). It follows that a rise in $\left[\mathrm{K}^{1}\right]_{\mathrm{o}}$ and depolarization, along with an increase in $\left[\mathrm{Na}^{1}\right] \mathrm{i}$, will promote reverse operation of this transporter and the release of glutamate from cytoplasmic compartments. Indeed, central axons damaged by either anoxia or trauma suffer marked depletion of $\mathrm{K}^{1}$ and accumulation of $\mathrm{Na}^{1}$ (LoPachin and Stys, 1995), with an expected rise in $\left[\mathrm{K}^{1}\right]_{\mathrm{o}}$ and depolarization (Ransom et al., 1992; Leppanen and Stys, 1997), stimuli that would strongly favor reversal of $\mathrm{Na}^{1}$-dependent glutamate transport. This hypothesis was supported by the markedly neuroprotective effects of the transport inhibitors dihydrokainate and L-trans-pyrrolidine-2,4dicarboxylic acid. Moreover, immunohistochemistry for glutamate revealed that anoxic axon cylinders, and to a lesser extent oligodendrocytes, are the main source of endogenous glutamate (Fig. $4 E$ ); the efflux of glutamate from these

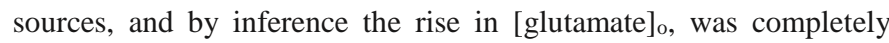
prevented by pharmacological inhibition of $\mathrm{Na}^{1}$-dependent glutamate transport. Notably, astrocytic glutamate was unchanged by anoxia, in keeping with the relative resistance of ionic deregulation by anoxia alone in this cell type (Rose et al., 1998).

The above mechanism, possibly representing an exaggeration of a normal physiological release of glutamate as proposed for neonatal optic nerve axons (Kriegler and Chiu, 1993), could also account for the rise in [glutamate] in white matter of ischemic cat brain (Graf et al., 1998) and may contribute to the demyelination and white matter degeneration found after traumatic brain injury (Povlishock and Christman, 1995; Maxwell et al., 1997). Moreover, if myelin is a significant target for glutamate toxicity as our results suggest, the submyelinic spaces where diffusion is restricted could harbor very high glutamate levels. Using anoxic CNS axons as a well characterized example, assuming a depolarization to $230 \mathrm{mV}$ (Leppanen and Stys, 1997), $\left[\mathrm{Na}^{1}\right]_{\mathrm{i}},\left[\mathrm{Na}^{1}\right]_{\mathrm{o}},\left[\mathrm{K}^{1}\right]_{\mathrm{i}}$, and $\left[\mathrm{K}^{1}\right]_{\mathrm{o}}$ of $100,150,15$, and $15 \mathrm{~mm}$, respectively (Ransom et al., 1992; LoPachin and Stys, 1995), a ratio of $\left[\mathrm{H}^{1}\right]_{\mathrm{i}}$ to $\left[\mathrm{H}^{1}\right]_{\mathrm{o}}$ of 2.5 (with both moving proportionally in the acid direction during injury), [glutamate] $53 \mathrm{~mm}$ (Attwell et al., 1993), and a transporter stoichiometry of $3 \mathrm{Na}^{1}, 1 \mathrm{H}^{1}, 1$ glutamate $2: 1 \mathrm{~K}^{1}$ (Levy et al., 1998), Equation 1 predicts that [glutamate]o will exceed $230 \mathrm{~mm}$ at equilibrium; this ignores any reductions in $\left[\mathrm{Na}^{1}\right]_{\mathrm{o}}$, which would steeply push [glutamate] to even higher levels. Similar ionic deregulation in mechanically injured spinal cord slices (Blight and LoPachin, 1998) implies an equally potent stimulus for reverse $\mathrm{Na}^{1}$-glutamate transport in trauma as well: 


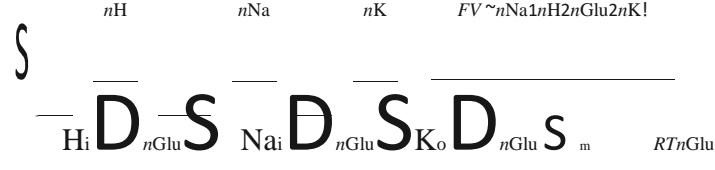

D

Gluo 5 GluiHo

Nao $\quad \mathrm{K}_{\mathrm{i}} \quad e$

where $X_{\mathrm{o}}$ and $X_{\mathrm{i}}$ are extracellular and intracellular ionic concentrations, $n X$ are stoichiometries, and $V_{\mathrm{m}}$ is membrane potential.

Pharmacological evidence for the presence of $\mathrm{Na}^{1}$-dependent glutamate transport was supported by immunohistochemical staining for all three isoforms in spinal dorsal columns, consistent with previous studies that also found evidence for EAAC1, GLAST, and GLT1 in CNS white matter (Sutherland et al., 1996; Choi and Chiu, 1997). Dihydrokainate is a specific inhibitor of the GLT1 isoform (Arriza et al., 1994). The neuroprotective effect of this agent might suggest a purely glial source of glutamate efflux mediated by GLT1; however, recent reports indicate that GLT1 may be present in neurons as well (Schmitt et al., 1996; Mennerick et al., 1998). Our data (Fig. 5) also indicate that this isoform is present in the axoplasm, possibly for transport to the terminals or for insertion into the axolemma along the length of the fiber. Demonstration of the presence of glutamate transporters on the axolemma will likely require the high spatial resolution of immunoelectronmicroscopy.

The present study indicates that the ionic and membrane potential perturbations experienced by dorsal column axons, and possibly glia, in response to in vitro anoxia or mechanical trauma, are more than sufficient to induce toxic efflux of glutamate through reversal of $\mathrm{Na}^{1}$ dependent glutamate transport. This uncontrolled release of glutamate, potentially into restricted spaces under the myelin, activates AMPA receptors, causing damage to the sheath and possibly other structures. This novel mechanism of injury may be very important for the future design of neuroprotectants in SCI, particularly if molecular design techniques succeed in developing a relatively specific blocker of the glutamate efflux mode mediated by glutamate transporters.

\section{REFERENCES}

Agrawal SK, Fehlings MG (1996) Mechanisms of secondary injury to spinal cord axons in vitro-role of Na1, Na1-K1-ATPase, the Na1-H1 exchanger, and the Na1-Ca21 exchanger. J Neurosci

$16: 545-552$.

Agrawal SK, Fehlings MG (1997) Role of NMDA and non-NMDA ionotropic glutamate receptors in traumatic spinal cord axonal injury. J Neurosci 17:10551063.

Arriza JL, Fairman WA, Wadiche JI, Murdoch GH, Kavanaugh MP, Amara SG (1994) Functional comparisons of three glutamate transporter subtypes cloned from human motor cortex. J Neurosci 14:5559-5569.

Attwell D, Barbour B, Szatkowski M (1993) Nonvesicular release of neurotransmitter. Neuron 11:401-407.

Blight AR, LoPachin RM (1998) Experimental spinal cord injury: characterization of axonal element and water perturbations. Soc Neurosci Abstr 24:251.

Choi I, Chiu SY (1997) Expression of high-affinity neuronal and glial glutamate transporters in the rat optic nerve. Glia 20:184-192.

Fonnum F (1984) Glutamate: a neurotransmitter in mammalian brain. J Neurochem 42:1-11.

Furuta A, Rothstein JD, Martin LJ (1997) Glutamate transporter protein subtypes are expressed differentially during rat CNS development. J Neurosci 17:8363-8375.

Gibson CJ (1992) Overview of spinal cord injury. Phys Med Rehab Clin North Am 3:699-709.

Graf R, Dohmen C, Kumura E, Rosner G, Heiss W-D (1998) Extracellular shifts of GABA, adenosine and ion activities in cortical gray and subcortical white matter during global ischemia in cats. Soc Neurosci Abstr 24:983.
Griffiths R, Dunlop J, Gorman A, Senior J, Grieve A (1994) L-transPyrrolidine2,4-dicarboxylate and cis-1-aminocyclobutane-1,3dicarboxylate behave as transportable, competitive inhibitors of the high-affinity glutamate transporters. Biochem Pharmacol 47:267-274.

Imaizumi T, Kocsis JD, Waxman SG (1997) Anoxic injury in the rat spinal cord-pharmacological evidence for multiple steps in Ca21dependent injury of the dorsal columns. J Neurotrauma 14:299-311.

Kriegler S, Chiu SY (1993) Calcium signaling of glial cells along mammalian axons. J Neurosci 13:4229-4245.

Leppanen LL, Stys PK (1997) Ion transport and membrane potential in CNS myelinated axons. II: effects of metabolic inhibition. J Neurophysiol 78:2095-2107.

Levy LM, Warr O, Attwell D (1998) Stoichiometry of the glial glutamate transporter GLT-1 expressed inducibly in a Chinese hamster ovary cell line selected for low endogenous Na1-dependent glutamate uptake. J Neurosci 18:9620-9628.

LoPachin RM, Stys PK (1995) Elemental composition and water content of rat optic nerve myelinated axons and glial cells: effects of in vitro anoxia and reoxygenation. J Neurosci 15:6735-6746.

Matsuo A, Lee GC, Terai K, Takami K, Hickey WF, McGeer EG, McGeer PL (1997) Unmasking of an unusual myelin basic protein epitope during the process of myelin degeneration in humans: a potential mechanism for the generation of autoantigens. Am J Pathol 150:1253-1266.

Matute C, Sanchez-Gomez MV, Martinez-Millan L, Miledi R (1997) Glutamate receptor-mediated toxicity in optic nerve oligodendrocytes. Proc Natl Acad Sci USA 94:8830-8835.

Maxwell WL, Povlishock JT, Graham DL (1997) A mechanistic analysis of nondisruptive axonal injury: a review. J Neurotrauma 14:419-440.

McDonald JW, Althomsons SP, Hyrc KL, Choi DW, Goldberg MP (1998) Oligodendrocytes from forebrain are highly vulnerable to

AMPA/kainate receptor-mediated excitotoxicity. Nat Med 4:291-297.

Mealing GA, Lanthorn TH, Murray CL, Small DL, Morley P (1999) Differences in degree of trapping of low-affinity uncompetitive $N$-methyl-D-aspartic acid receptor antagonists with similar kinetics of block. J Pharmacol Exp Ther 288:204-210.

Mennerick S, Dhond RP, Benz A, Xu W, Rothstein JD, Danbolt NC, Isenberg KE, Zorumski CF (1998) Neuronal expression of the glutamate transporter GLT-1 in hippocampal microcultures. J Neurosci 18:4490-4499.

Paternain AV, Morales M, Lerma J (1995) Selective antagonism of AMPA receptors unmasks kainate receptor-mediated responses in hippocampal neurons. Neuron 14:185-189.

Povlishock JT, Christman CW (1995) Diffuse axonal injury. In: The axon: structure, function and pathophysiology (Waxman SG, Kocsis JD, Stys PK, eds), pp 504-529. New York: Oxford UP.

Ransom BR, Waxman SG, Davis PK (1990) Anoxic injury of CNS white matter: protective effect of ketamine. Neurology 40:1399-1403.

Ransom BR, Walz W, Davis PK, Carlini WG (1992) Anoxia-induced changes in extracellular $\mathrm{K}^{1}$ and $\mathrm{pH}$ in mammalian central white matter. J Cereb Blood Flow Metab 12:593-602.

Roettger V, Lipton P (1996) Mechanism of glutamate release from rat hippocampal slices during in vitro ischemia. Neuroscience 75:677-685. Rose CR, Waxman SG, Ransom BR (1998) Effects of glucose deprivation, chemical hypoxia, and simulated ischemia on $\mathrm{Na}^{1}$ homeostasis in rat spinal cord astrocytes. J Neurosci 18:3554-3562.

Rosenberg LJ, Teng YD, Wrathall JR (1999) 2,3-dihydroxy-6-nitro7sulfamoyl-benzo $(f)$ quinoxaline reduces glial loss and acute white matter pathology after experimental spinal cord contusion. J Neurosci 19:464-475.

Rothstein JD, Martin L, Levey AI, Dykes-Hoberg M, Jin L, Wu D, Nash N, Kuncl RW (1994) Localization of neuronal and glial glutamate transporters. Neuron 13:713-725.

Rutledge EM, Aschner M, Kimelberg HK (1998) Pharmacological characterization of swelling-induced $\mathrm{D}-\left[{ }^{3} \mathrm{H}\right]$ aspartate release from primary astrocyte cultures. Am J Physiol 274:C1511-C1520.

Schmitt A, Asan E, Puschel B, Jons T, Kugler P (1996) Expression of the glutamate transporter GLT1 in neural cells of the rat central nervous system: non-radioactive in situ hybridization and comparative immunocytochemistry. Neuroscience 71:989-1004.

Stys PK (1994) WaveTrak: a data acquisition system and waveform database for the Macintosh. Sci Comput Automation 10:19-24.

Stys PK, LoPachin RM (1998) Mechanisms of ion flux in anoxic myelinated CNS axons. Neuroscience 82:21-32.

Stys PK, Waxman SG, Ransom BR (1992) Ionic mechanisms of anoxic 
injury in mammalian CNS white matter: role of $\mathrm{Na}^{1}$ channels and $\mathrm{Na}^{1}-\mathrm{Ca}^{21}$ exchanger. J Neurosci 12:430-439.

Sutherland ML, Delaney TA, Noebels JL (1996) Glutamate transporter mRNA expression in proliferative zones of the developing and adult murine CNS. J Neurosci 16:2191-2207.

Tator CH, Koyanagi I (1997) Vascular mechanisms in the pathophysiology of human spinal cord injury. J Neurosurg 86:483-492.

Teng YD, Wrathall JR (1997) Local blockade of sodium channels by tetrodotoxin ameliorates tissue loss and long-term functional deficits resulting from experimental spinal cord injury. J Neurosci 17:4359-4366.

Trapp BD, Bernier L, Andrews SB, Colman DR (1988) Cellular and subcellular distribution of 29,39-cyclic nucleotide 39-phosphodiesterase and its mRNA in the rat central nervous system. J Neurochem 51:859-868.

Wrathall JR, Choiniere D, Teng YD (1994) Dose-dependent reduction of tissue loss and functional impairment after spinal cord trauma with the AMPA/kainate antagonist NBQX. J Neurosci 14:6598-6607.

Wrathall JR, Teng YD, Marriott R (1997) Delayed antagonism of AMPA/kainate receptors reduces long-term functional deficits resulting from spinal cord trauma. Exp Neurol 145:565-573.

Zerangue N, Kavanaugh MP (1996) Flux coupling in a neuronal glutamate transporter. Nature 383:634-637. 